\title{
Inverse patterns in successful finger-maze acquisition performance by right-handed males and left-handed females
}

\author{
GERI R. ALVIS, JEANNETTE P. WARD, and DEANNA L. DODSON \\ Memphis State University, Memphis, Tennessee \\ and \\ ROBERT L. PUSAKULICH \\ Veterans Administration Medical Center, Memphis, Tennessee
}

\begin{abstract}
In a finger-maze acquisition task, $23 \%$ of 197 potential subjects failed to meet time criteria. The pattern of acquisition across different handedness-sex groups suggests that weaker lateralization and greater bihemispheric dominance in association with non-righthandedness or female sex may have adversely influenced finger-maze acquisition performance. The one exception to the expected pattern was that the proportion of left-handed female acquirers was very similar to that of right-handed males. These results may reflect a stronger lateralization to and dominance of the right cerebral hemisphere in left-handed females, in a unique inversion to that in righthanded males.
\end{abstract}

Results from a recent study (Ward, Alvis, Sanford, Dodson, \& Pusakulich, 1989) implied that variations in cerebral lateralization and hand dominance may govern differential use of left- and right-hemisphere cognitive strategies on a finger-maze acquisition task. In that study, a number of potential subjects exceeded the designated time limits in performing the finger-maze acquisition task. The time criteria these nonacquirers failed to meet were found to exceed the mean time required by the slowest successful group to master the task by three standard deviations. Since handedness appeared to play a role in successful finger-maze acquisition learning, this factor may also be implicated in the deviant performances of nonacquiring subjects. Furthermore, since males may be more strongly lateralized for language and spatial functions than are females (Bryden, 1982; Corballis, 1983; Springer \& Deutsch, 1985), sex also may distinguish between fingermaze acquirers and nonacquirers. To examine possible relationships between handedness and/or sex and fingermaze acquisition versus nonacquisition, the distributions of acquirers and nonacquirers in the different handedness-sex groups of the Ward et al. (1989) study were analyzed.

\section{METHOD}

\section{Subjects}

During several phases of an extended study on tactuospatial fingermaze performance, a large number of Memphis State University psychology students had volunteered as subjects for extra course credit. The 127 female and 70 male subjects for whom both handedness and sex information was available constituted the sample used in the present

Correspondence may be addressed to Jeannette P. Ward, Department of Psychology, Memphis State University, Memphis, TN 38152. analysis; of these subjects, 97 were right-handed, 66 were left-handed, and 34 were ambidextrous.

\section{Test Materials and Apparatus}

Hand dominance (or preference for ambidexters) was determined with a lateral dominance questionnaire (Lawson, Goldstein, \& Musty, 1975), and was also verified verbally. Lateralization to the right or left of 8 or more of the 12 questionnaire items was required for subjects to be classified as right- or left-handed; otherwise, subjects were classified as ambidextrous.

The plywood finger maze consisted of one pathway with five cul-desacs between the circular start and goal boxes; complete specifications and an illustration are provided in the report of Ward et al. (1989).

\section{Procedure}

In individual sessions, the finger maze was uncovered after the subject had been blindfolded. The task was explained as learning to run the maze one time from the startbox to the goalbox without entering any cul-de-sac, with accuracy as the most critical performance measure. As one of the conditions of the extencled study, all subjects included in the present analysis performed the lask with the nondominant or nonpreferred hand (for ambidexters, the right hand in most cases).

The experimenter guided the index finger of each subject's nondominant or nonpreferred hand through the maze one time, entering each cul-de-sac in sequence along the correit pathway from the startbox to the goalbox. For subsequent trials, the same finger was placed in the startbox and the prompt "go" was given. Trials continued until either one error-free run was achieved, or the time limits $(5 \mathrm{~min}$ for any single trial; $10 \mathrm{~min}$ for total number of trials) that were imposed to minimize possible fatigue or frustration effects had been exceeded. Performance measures for each trial includid an error score any time a subject's finger entered any cul-de-sac, and the time elapsed between the initial prompt and arrival at the goalbox. Failure to meet the designated time limits constituted nonacquisition.

\section{RESULTS}

Of the 197 potential subjects, 45 (23\%) failed to master the finger-maze acquisition task within the time limits. An interesting pattern in the proportional distribution of 


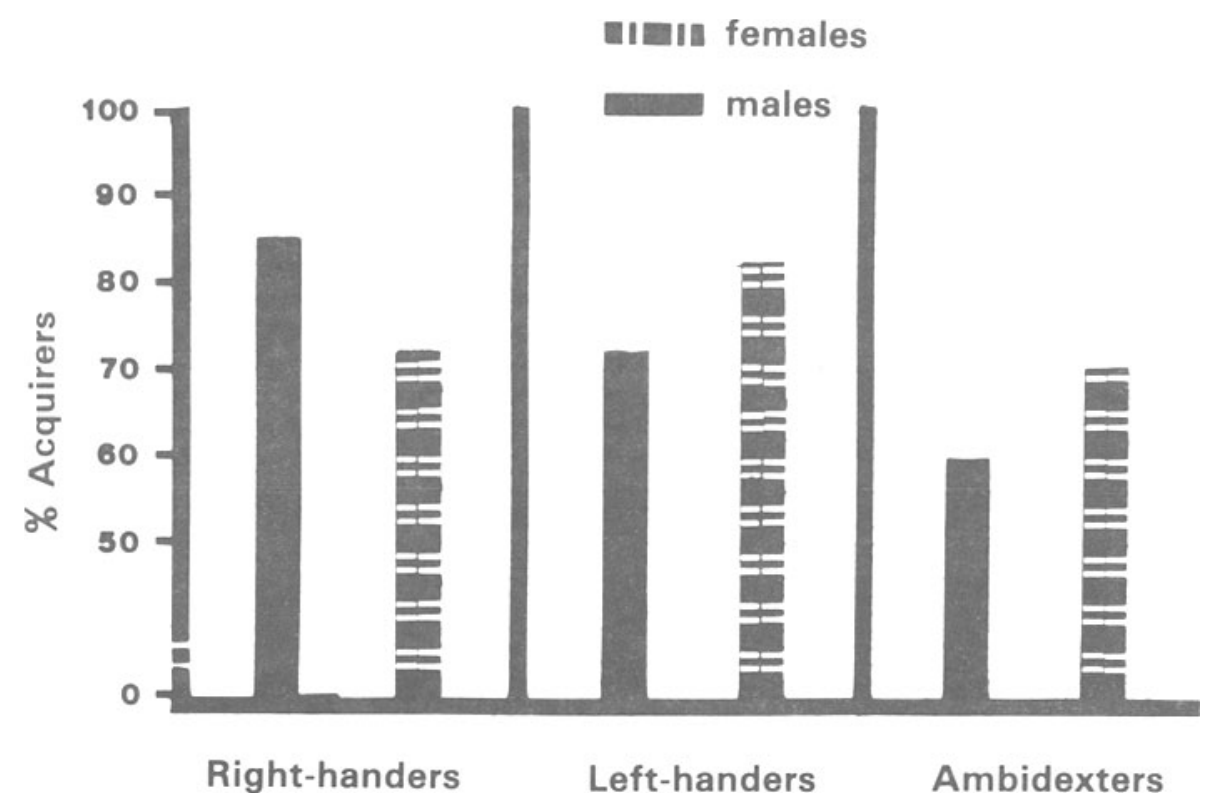

Figure 1. Proportional finger-maze acquisition rates in the six different handedness-sex groups; proportions are almost exactly reversed for right- and left-handed males and females.

acquirers as a function of handedness-sex was observed: for right- and left-handers, the proportions of male and female acquirers were almost exactly reversed (see Figure 1). Eighty-five percent of the right-handed males $(N=39)$ acquired the task successfully, as did $82 \%$ of the left-handed females $(N=45)$. The right-handed female and left-handed male groups had lower and nearly equal acquisition rates $(72 \%, N=58$, and $71 \%, N=$ 21 , respectively). The acquisition rate in the female ambidextrous group was also in the $70 \%$ range $(71 \%, N=$ 24), and male ambidexters demonstrated the lowest proportion of acquirers $(60 \%, N=10)$. Chi-square analyses indicated that handedness or sex, alone or combined, did not differentiate significantly between proportions of acquirers in the six handedness-sex groups.

\section{DISCUSSION}

Approximately one quarter of the subjects in this analysis exceeded the finger-maze acquisition task time limits (i.e., they exceeded by three standard deviations the slowest mean time required by successfully acquiring subjects). Although the differences in proportions of acquiring subjects in the six handedness-sex groups were not shown to be of statistical significance, the demonstrated distributional pattern of successful finger-maze acquistion warrants some consideration. The near equivalence of the left-handed female and right-handed male groups' proportions of acquirers (both more than $80 \%$ ) seems suggestive in view of nearly identical lower proportions of approximately $70 \%$ shown by the right-handed female, left-handed male, and ambidextrous female groups. The even lower proportion of the ambidextrous male group may well be attributable to the considerably smaller size of that group.

Acquisition in the six handedness-sex groups may reflect the proposed stronger hemispheric lateralization in right-handers as compared to lefthanders or ambidexters, and in males as compared to females (Bryden, 1982; Corballis, 1983; Springer \& Deutsch, 1985). Weaker lateralization, with greater bihemispheric dominance and control, may increase the potential for interhemispheric conflict and thus lead to less efficient use of cognitive strategies pertinent to finger-maze acquisition performance. Alternatively, less well-developed spatial capability may be a factor; this is suggested by reports (Levy, Trevarthen, \& Sperry, 1972; Teng \& Sperry, 1973; however, see Corballis, 1983) that language representation in both hemispheres may "crowd out" spatial representation in the right hemisphere, and thus hinder the maximal development of that function.

If successful finger-maze acquisition performance is facilitated by stronger cerebral lateralization and dominance, then the right-handed males would indeed be expected to yield the largest proportion of acquirers, due to their more pronounced lateralization. However, the further expectation that the acquisition rates of all other groups would similarly show adverse effects of weaker lateralization and dominance met with one notable exception: the acquisition rate of the left-handed females was very comparable to that of the right-handed males, rather than to the lower rates of the other females and non-right-handed males as would have been predicted.

It may be that in the left-handed female subjects, the two factors that each singly seem to foster some language representation in the right hemisphere (i.e., non-righthandedness and femaleness) jointly produced a right-hemisphere language representation and dominance, accompanied by stronger lateralization of spatial functioning to the left hemisphere. If the language lateralization and dominance in left-handed females were as strongly right-hemispheric as it is left-hemispheric in right-handed males, and if it were associated with less interhemispheric conflict and more efficient use of spatial and/or cognitive strategy abilities, then this might be reflected in higher acquisition rates in both of these groups.

This conceptualization of a unique inversion in left-handed females of the right-handed males' greater language lateralization to and dominance of the left hemisphere has some empirical support. In one study (Piazza, 1980) in which males showed the greater left-hemisphere lateralization for speech, stronger right-hemisphere lateralization for nonspeech auditory stimuli was demonstrated in right-handed but not lefthanded females. Furthermore, the findings of another study (Galin, Ornstein, Herron, \& Johnstone, 1982) indicated that the EEG alpha asymmetry pattern (greater right:left ratio for a language task vs. a blockdesign task) demonstrated by right-handers was not only less strong in left-handers, but was actually reversed in many left-handed females; these authors even refer to the "reverse laterality" of left-handed females.

The post hoc analysis presented here pertains to subjects who performed the finger-maze acquisition task with the nondominant or non- 
preferred hand. Continued research, including studies with subjects using the dominant or preferred hand, seems desirable to examine further the possibility of an inverse lateralization and dominance in left-handed females compared to right-handed males. That possibility moreover implies that particular attention should be paid to the performances of lefthanded females in any study that investigates differences in handedness and sex, or in cerebral lateralization and dominance.

\section{REFERENCES}

Bryden, M. P. (1982). Laterality: Functional asymmetry in the intact brain. New York: Academic Press.

Corballis, M. C. (1983). Human laterality. New York: Academic Press.

Galin, D., Ornstein, R., Herron, J., \& Johnstone, J. (1982). Sex and handedness differences in EEG measures of hemispheric specialization. Brain \& Language, 16, 19-55.

Lawson, R. B., Goldstein, S. G., \& Musty, R. E. (1975). Experiments in psychology: Laboratory manual and kit to accompany Prin- ciples and Methods of Psychology. New York: Oxford University Press.

Levy, J., Trevarthen, C., \& SPerry, R. N. (1972). Perception of bilateral chimeric figures following hemispheric deconnexion. Brain, 95, 61-68

Piazza, D. M. (1980). The influence of sex and handedness in the hemispheric specialization of verbal and nonverbal tasks. Neuropsychologia, 18, 163-176.

SPRINGER, S. P., De DUTSCh, G. (1985). Lefi brain, right brain (rev. ed.). New York: W. H. Freeman.

TENG, E. L., \&PERRY, R. W. (1973). Interhemispheric interaction during simultaneous bilateral presentation of letters or digits in commissurotomized patients. Neuropsychologicl, 11, 131-140.

Ward, J. P., Alvis, G. R., SAnford, C. G., Dodson, D. L., \& Pusakulich, R. L. (1989). Qualitative differences in tactuo-spatial motor learning in left-handers. Neuropsychologia, 27, 1091-1099.

(Manuscript received February 9, 1990.) 